\title{
Study of storm weather situations in observation and ECHAM3/T42 model simulation
}

\section{Udo Busch, Björn-Rüdiger Beckmann \& Rainer Roth}

To cite this article: Udo Busch, Björn-Rüdiger Beckmann \& Rainer Roth (1998) Study of storm weather situations in observation and ECHAM3/T42 model simulation, Tellus A: Dynamic Meteorology and Oceanography, 50:4, 411-423, DOI: 10.3402/tellusa.v50i4.14541

To link to this article: http://dx.doi.org/10.3402/tellusa.v50i4.14541 \section{(c) 1998 The Author(s). Published by Taylor \&
Francis.}

曲 Published online: 15 Dec 2016.

Submit your article to this journal $\pi$

\section{Џll Article views: 1}




\title{
Study of storm weather situations in observation and ECHAM3/T42 model simulation
}

\author{
By UDO BUSCH ${ }^{1, *}$, BJÖRN-RÜDIGER BECKMANN ${ }^{2}$ and RAINER ROTH ${ }^{1}$, ${ }^{1}$ Institut für \\ Meteorologie und Klimatologie der Universität Hannover, Herrenhäuser Str. 2, D-30419 Hannover, \\ Germany; ${ }^{2}$ Institut für Meteorologie der Universität Leipzig, Stephanstraße 3, D-04103 Leipzig, Germany
}

(Manuscript received 2 September 1997; in final form 14 April 1998)

\begin{abstract}
In this paper, we provide an estimation of the seasonal distribution of strong wind and storm weather situations in an ECHAM3/T42 climate model simulation in relation to observed conditions. Observational data of the German Bight and the southern Baltic Sea are taken to compare observations and climate model simulation. The results of the study show significant differences in the seasonal frequency of occurrence for strong wind and storm weather situations between simulation and observations. A new objective classification routine for detecting single strong wind and storm weather situations (Bft 7 and more) in coarse resolution models is used to validate the large-scale parameters of those events in the climate simulation. The objective classification routine is able to detect strong wind and storm weather situations of two flow regimes in the German Bight in winter. The routine is applied to the ECMWF Re-Analysis ( $\mathrm{T} 42$ resolution) and to a climate simulation of the northern Hemisphere, which was performed with the ECHAM3/T42. It is shown that the large-scale parameters of single strong wind and storm weather situations are simulated quite realistically in the ECHAM3/T42.
\end{abstract}

\section{Introduction}

In the current climate discussion, the frequency and intensity of strong wind and storm weather situations are becoming more and more relevant (Bengtsson et al., 1996; König et al., 1993). Regarding studies in investigations on the field of coastal morphodynamics and coast protection (Von Storch and Reichardt, 1997) there is considerable interest as to whether the seasonal distribution of strong wind and storm weather situations changes in an altered climate or not. In order to examine this, it is convenient to use global climate models like the Hamburg ECHAM3/T42 (DKRZ, 1994). First of all, we need to discuss the issue of whether a general circulation model (GCM) like

\footnotetext{
* Corresponding author. e-mail: busch@nevados.muk.uni-hannover.de
}

the ECHAM3/T42 is able to reproduce the largescale parameters which are necessary for strong wind or storm weather situations in the selected area. The large-scale parameters of single strong wind or storm weather situations in the climate model simulation are compared with observations in this study. The aim of the paper is to examine whether the seasonal distribution of strong wind and storm weather situations is the same as in observations for the region of the German Bight and the southern Baltic Sea. In order to achieve this, the ECHAM3/T42 control run (CTRL), the ECMWF Re-Analysis, surface and upper level weather maps of the area of the North Atlantic and Europe as well as observations in the German Bight and the southern Baltic Sea are considered. If the seasonal distribution of strong wind and storm weather situations in the CTRL is not the same as in observations, this has to be taken into 
consideration in regional climate studies of this problem. A possible change in the seasonal distribution of strong wind and storm weather situations in a double or threefold $\mathrm{CO}_{2}$-scenario in relation to the CTRL has to be discussed additionally in view of the knowledge that there are differences between observations and climate model simulation.

The present paper contains two methods of comparing model output and observations. First, the seasonal distribution of strong wind and storm weather situations in simulation and observations is compared. To test the seasonal distribution of these events, cases with wind speeds between $10.5 \mathrm{~m} \mathrm{~s}^{-1}$ and $14 \mathrm{~m} \mathrm{~s}^{-1}$ (Bft 6) and with more than $14 \mathrm{~m} \mathrm{~s}^{-1}$ (Bft 7 and more) at a height of $10 \mathrm{~m}$ are selected. For the calculation of the confidence level of the seasonal distribution a method devised by Dukes and Palutikof (1995) is used.

Second, a new objective classification routine for detecting single strong wind and storm weather situations (Bft 7 and more) in coarse resolution models is used (Zielke et al., 1997). The routine is able to detect strong wind and storm weather situations of two flow regimes. The criteria of this classification routine are laid down using the evaluation of storm weather situations in observations of the period 1949 to 1996. In order to achieve this, surface and upper level weather maps of the area of the North Atlantic and Europe as well as observations and measurements of several weather stations in the German Bight are considered. The routine is applied to the ECMWF Re-Analysis (T42 resolution) and to a climate simulation of the northern Hemisphere, which is performed with the atmosphere model ECHAM3/T42. In order to decide whether a weather situation is one which causes a strong wind or storm weather situation several meteorological large-scale parameters are considered. Only if all the criteria laid down in observations are fulfilled is the decision positive. This new objective classification routine is used to validate the largescale parameters of single strong wind and storm weather situations in the climate model simulation.

\section{Data}

\subsection{Model data}

The model data were generated by the Hamburg spectral atmospheric general circulation model
ECHAM3 from the Max-Planck-Institut für Meteorologie Hamburg (MPI-Hamburg) and the Deutsches Klimarechenzentrum (DKRZ). The ECHAM was developed from the ECMWF model. It was subjected to several changes, mostly in parameterization, in order to adjust the model to climate simulation. T42 is chosen as the reference resolution (Gaussian grid with $2.8^{\circ}$ ), even though the model uses resolutions in the range of T21 (Gaussian grid with $5.6^{\circ}$ ) to T106 (Gaussian grid with $1.1^{\circ}$ ) (DKRZ, 1994). Prognostic variables are vorticity, divergence, temperature, surface pressure, water vapour and cloud water content. The atmosphere is vertically represented by a 19-layer hybrid coordinate system with second-order finite differences. The roughness length over sea is calculated by the Charnock formula in accordance with Miller (1992). More detailed information in particular with regard to the physical parameterization of the radiation, clouds and precipitation, convection and vertical and horizontal diffusion is given by Roeckner et al. (1992).

The model run which was selected for the present investigation is the so-called control run (CTRL) in T42 resolution. At present, this model run has provided the highest spatial resolution there is for a permanent 30-year time series. The CTRL used a climatological sea surface temperature (SST). Therefore each model year uses the identical annual cycle of the mean climatological SST (Sausen et al., 1995). The atmospheric $\mathrm{CO}_{2}$ concentration taken from the year 1985 is constant in the CTRL (Cubasch et al., 1992).

In order to compare the observational surface data with the model run, three grid points of the area of the German Bight and the southern Baltic Sea were selected. The geographical positions of these grid points are: GP I $5.6^{\circ} \mathrm{E}$ and $57.2^{\circ} \mathrm{N}$, GP II $5.6^{\circ} \mathrm{E}$ and $54.4^{\circ} \mathrm{N}$, GP III $8.4^{\circ} \mathrm{E}$ and $57.2^{\circ} \mathrm{N}$, GP IV $14.1^{\circ} \mathrm{E}$ and $54.4^{\circ} \mathrm{N}$, GP $\mathrm{V} 16.9^{\circ} \mathrm{E}$ and $57.2^{\circ} \mathrm{N}$ and GP VI $19.7^{\circ} \mathrm{E}$ and $57.2^{\circ} \mathrm{N}$. Each model grid point represents a sea surface with land surface grid points surrounding it. In this study only the seasonal distribution divided into observations and climate model simulation is discussed. For further regional climate studies with the output of complex climate models like the ECHAM3 an additional downscaling strategy is needed (Von Storch, 1995). The available data for the study are the calculated values of the wind speed at 00 and 12 UTC, which were stored by 
the MPI-Hamburg during the simulation of the ECHAM3/T42 CTRL for every model year from 11 to 40. However, uninterrupted long-term-series of measurements in the area of the German Bight were only available at 12 UTC. That is why only this time was taken into account for the investigations in this study.

In contrast to observations, time series of climate model simulations last 30 days each month, i.e., every model year runs 360 days. Therefore, a small difference in the period between observational and modelled data is obtained. The smallest difference is obtained in winter (6-7 days for 30 years) and the largest one for spring and summer (60 days for 30 years). Considering the fact that the reference level for observational measured wind speed is $10 \mathrm{~m}$ the same height is chosen for the climate model. The $10 \mathrm{~m}$ wind speed in the climate model simulation is calculated using the logarithmic wind profile. The shearing stress speed $u_{*}$ is calculated with the lowest model level wind speed $(\approx 40 \mathrm{~m})$ multiplied by a drag coefficient $C_{\mathrm{D}}$. This coefficient depends on the criteria of stability and roughness length (DKRZ, 1994).

\subsection{Observational data}

Observational data were taken from the weather stations Norderney and Boltenhagen (German Weather Service, DWD) and from the ECMWF Re-Analysis data of the period 1979 to 1993 . Tenminute-average wind speeds of the period 1949 to 1996 are available for the Norderney station and of the period 1973 to 1993 for the Boltenhagen station. At Norderney there are continous measurements only at 06, 09, 12 and 15 UTC. The time periods chosen for this study relate to Norderney from 1966 to 1995 and in the case of Boltenhagen from 1973 to 1993.

The Norderney and Boltenhagen observational data show inhomogeneities caused by different measurement heights and positions. Another important aspect is the surface roughness in the area adjacent to the wind measuring tower. This has to be considered if observational data are compared with results from model simulations. In this work results of a study from the DWD (Schmidt and Pätsch, 1992) were used to homogenize the measured wind speeds. With this method it is possible to transform the wind speed towards the open sea (10 km off the coast) at a reference height of $10 \mathrm{~m}$. The average error for the transformed wind speed is $\pm 5 \%$.

Fig. 1 shows the raw surface wind speed and the homogenized $10 \mathrm{~m}$ wind speed at Norderney and Boltenhagen. The raw surface wind speed of Norderney shows the change in the measurement height in 1978 and 1981. In 1978 the measurement height changed from $32 \mathrm{~m}$ to $21 \mathrm{~m}$ agl and in 1981 the change was from $21 \mathrm{~m}$ to $12 \mathrm{~m}$ agl. The German Weather Service (DWD) carried out a field experiment with a period of 4 years with the additional aid of numerical model simulations to calculate transfer coefficients of the wind speed as a function of the wind direction and the measurement heights of Norderney station (Schmidt and Pätsch, 1992). The results are transfer coefficients which give the $10 \mathrm{~m}$ wind speed over sea. The

a)

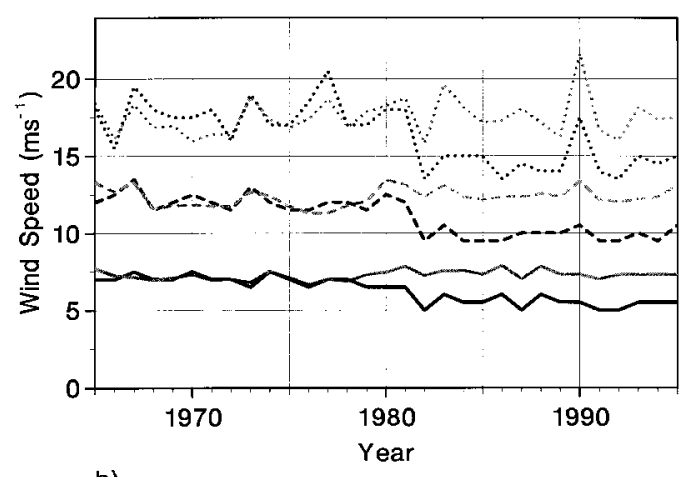

b)

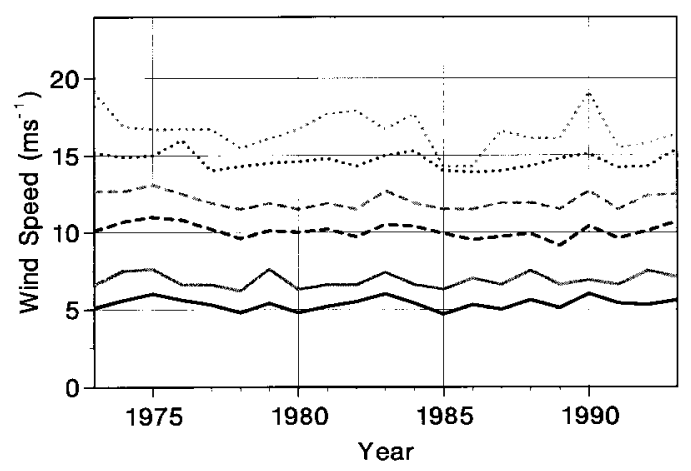

Fig. 1. The yearly average raw surface wind speed (grey lines) and the homogenized $10 \mathrm{~m}$ wind speed (black lines), 12 UTC. The solid lines are the $50 \%$ percentiles, the dashed lines the $10 \%$ and the dotted lines the $1 \%$ percentiles. (a) Norderney, (b) Boltenhagen. 
application of these transfer coefficients is shown in Fig. 1. For Boltenhagen the transfer coefficients were calculated in the same way. But for Boltenhagen there was no change in measurement height in the period 1973 to 1993 . The measurement height was constant at $18 \mathrm{~m}$ agl over the years.

\section{Methods}

\subsection{One-step Markov chain model}

The investigation into strong wind and storm weather situations is related to weather situations with a wind force of Bft 6 and those with Bft 7 and more. Table 1 shows the number of events for Norderney, Boltenhagen and the corresponding model grid points at 12 UTC in the periods considered. It can be seen that there are only noticable differences between observations and the climate model simulation for Boltenhagen and the corresponding model grid point for Bft 7 and more. To calculate the statistical significance of the seasonal distribution for these events, a technique developed by Kirchhoff and Kaminsky (Kirchhoff et al., 1989; Kaminsky et al., 1991) was used. This technique generates time series using the one-step Markov chain model.

The procedure for generating wind speeds with this model is based on a transitional probability matrix (TPM) for wind speed states. Initially, the wind speed time series is converted to a time series of wind speed states. The wind speed states which were used in this study are presented in Table 2. Once a wind speed state time series is produced, a TPM can be calculated. The TPM matrix (Table 3 ) shows the probability $p_{i j}$ of a wind speed

Table 1. Number of events with a wind force of Bft 6 and Bft 7 and more for Norderney, Boltenhagen and the corresponding model grid points at 12 UTC; the period is 30 years for the simulation and Norderney and 21 years for Boltenhagen

\begin{tabular}{lcc}
\hline & Wind force $=$ Bft 6 & Wind force $\geqslant$ Bft 7 \\
\hline Norderney & 1448 & 637 \\
Boltenhagen & 676 & 273 \\
GP II & 1367 & 596 \\
GP IV & 776 & 216 \\
\hline
\end{tabular}

Table 2. The division of wind speeds into wind speed states

\begin{tabular}{cc}
\hline $\begin{array}{c}\text { Wind speed } \\
\text { states }\end{array}$ & $\begin{array}{c}\text { Wind speed ff } \\
\left(\mathrm{m} \mathrm{s}^{-1}\right)\end{array}$ \\
\hline & \\
\hline & $\mathrm{ff}<1.5$ \\
3 & $1.5 \leqslant \mathrm{ff}<3.5$ \\
4 & $3.5 \leqslant \mathrm{ff}<5.5$ \\
5 & $5.5 \leqslant \mathrm{ff}<8.0$ \\
6 & $8.0 \leqslant \mathrm{ff}<10.5$ \\
7 & $10.5 \leqslant \mathrm{ff}<14.0$ \\
\hline
\end{tabular}

Table 3. One-step transition probability matrix (TPM)

$$
\left(\begin{array}{cccc}
p_{1,1} & p_{1,2} & \cdots & p_{1, k} \\
p_{2,1} & p_{2,2} & \cdots & p_{2, k} \\
\vdots & \vdots & p_{i, j} & \vdots \\
p_{k, 1} & p_{k, 2} & \cdots & p_{k, k}
\end{array}\right)
$$

in state $i$ at date $n$ changing to any state $j$ at date $n+1$, given $k$ wind speed intervals. An example of a TPM is shown in Table 4. A major advantage of the procedure is its simple application to the generation of wind speed time series. The procedure is summarized as follows. A starting wind speed state is selected, for example state 1 . Using the first row of the appropriate TPM, the next wind speed state is generated in a random manner according to the probabilities of that row. This can be most easily achieved by accumulating the probabilities along each row of the TPM. Using a uniform random number generator that produces a value between 0 and 1 , the next wind speed state can be generated. The generated state is the one where the random number is greater than the cumulative probability of the previous state but less than or equal to the cumulative probability of the subsequent state. In this way an infinite series of wind speed states can be generated. It is found that these synthetic series reproduce the original time series in mean, standard deviation and extreme values very well (Dukes and Palutikof, 1995). 
Table 4. The empirical transition probability matrix (TPM) for 7 wind speed states at Norderney in DJF. The TPM is derived from daily 12 UTC 10 m homogenized wind speeds in 1966 to 1995

\begin{tabular}{|c|c|c|c|c|c|c|c|}
\hline State & 1 & 2 & 3 & 4 & 5 & 6 & 7 \\
\hline 1 & 0.043 & 0.174 & 0.304 & 0.261 & 0.196 & 0.022 & 0.000 \\
\hline 2 & 0.035 & 0.121 & 0.260 & 0.260 & 0.225 & 0.075 & 0.023 \\
\hline 3 & 0.024 & 0.128 & 0.231 & 0.306 & 0.210 & 0.093 & 0.008 \\
\hline 4 & 0.018 & 0.077 & 0.185 & 0.338 & 0.227 & 0.115 & 0.041 \\
\hline 5 & 0.014 & 0.036 & 0.085 & 0.246 & 0.317 & 0.175 & 0.128 \\
\hline 6 & 0.009 & 0.028 & 0.068 & 0.196 & 0.313 & 0.236 & 0.150 \\
\hline 7 & 0.004 & 0.021 & 0.043 & 0.167 & 0.269 & 0.308 & 0.188 \\
\hline
\end{tabular}

\subsection{An objective classification routine for detecting strong wind and storm weather situations in coarse resolution models}

The objective classification routine (Zielke et al., 1997 ) is able to detect single strong wind or storm weather situations (Bft 7 and more) of two flow regimes for the area of the German Bight in winter. The criteria of this objective classification routine were laid down using the evaluation of storm weather situations in observations of the period 1949 to 1996. In order to achieve this, surface and upper level weather maps of the area of the North Atlantic and Europe as well as observations and measurements of several weather stations in the German Bight were considered. The routine is applied to the ECMWF Re-Analysis (T42 resolution) and to a climate simulation of the northern Hemisphere, which was performed with the atmosphere model ECHAM3/T42.

We classify the flow regimes of the strong wind and storm weather situations as a function of the accompanying European large-scale weather patterns ("Die Großwetterlagen Europas") by Hess and Brezowsky (Gerstengarbe et al., 1993) into two groups, the westerly and the northwesterly type. These groups contains the following European large-scale weather patterns: (a) westerly type: WZ, WA, WS, WW, SWZ and SWA; (b) northwesterly type: NZ, NA, NWZ, NWA and TRM.

In Section7, a description of the European largescale weather patterns used is given.

In Fig. 2b, d, the average geopotential heights of all the storm weather situations of the westerly and northwesterly types for the period 1979 to 1993 are shown. This is the available period for the ECMWF Re-Analysis data at present. The flow regime of the westerly type shows a high pressure area over the the central East Atlantic and the location of the steering centres are over Scandinavia, the Norwegian or the North Sea. The flow regime of the northwesterly type shows an Azores High northeastward shifted up to the westerly Biscay and the location of the steering centres are over Fennoscandinavia, the Norwegian or the Baltic Sea.

To make a decision as to whether a weather situation is one which causes a strong wind or storm weather situation in the German Bight, several meteorological large-scale parameters are considered taking into account the temporary shifting between the single criteria. This study has only been done for the German Bight, but the correlation for strong wind and storm weather situations between the German Bight and the southern Baltic Sea is $93 \%$ for the westerly and $88 \%$ for the northwesterly type. That means for example, that if there is a strong wind or storm weather situation of the westerly type in the southern Baltic Sea, there is one in the German Bight with $93 \%$ probability.

\subsubsection{The criteria of the classification routine}

Flow regime westerly type: Storm weather situations within a circulation pattern of the westerly type shows a high pressure area over the central East Atlantic. The location of the steering centre is over Scandinavia, the Norwegian or the North Sea. In our classification there has to be a difference of 45 gpdam between the low and the high pressure area. The way to detect the difference is to take 4 connected grid points with the lowest geopotential height of the area of the steering centre and 12 connected grid points of the high 

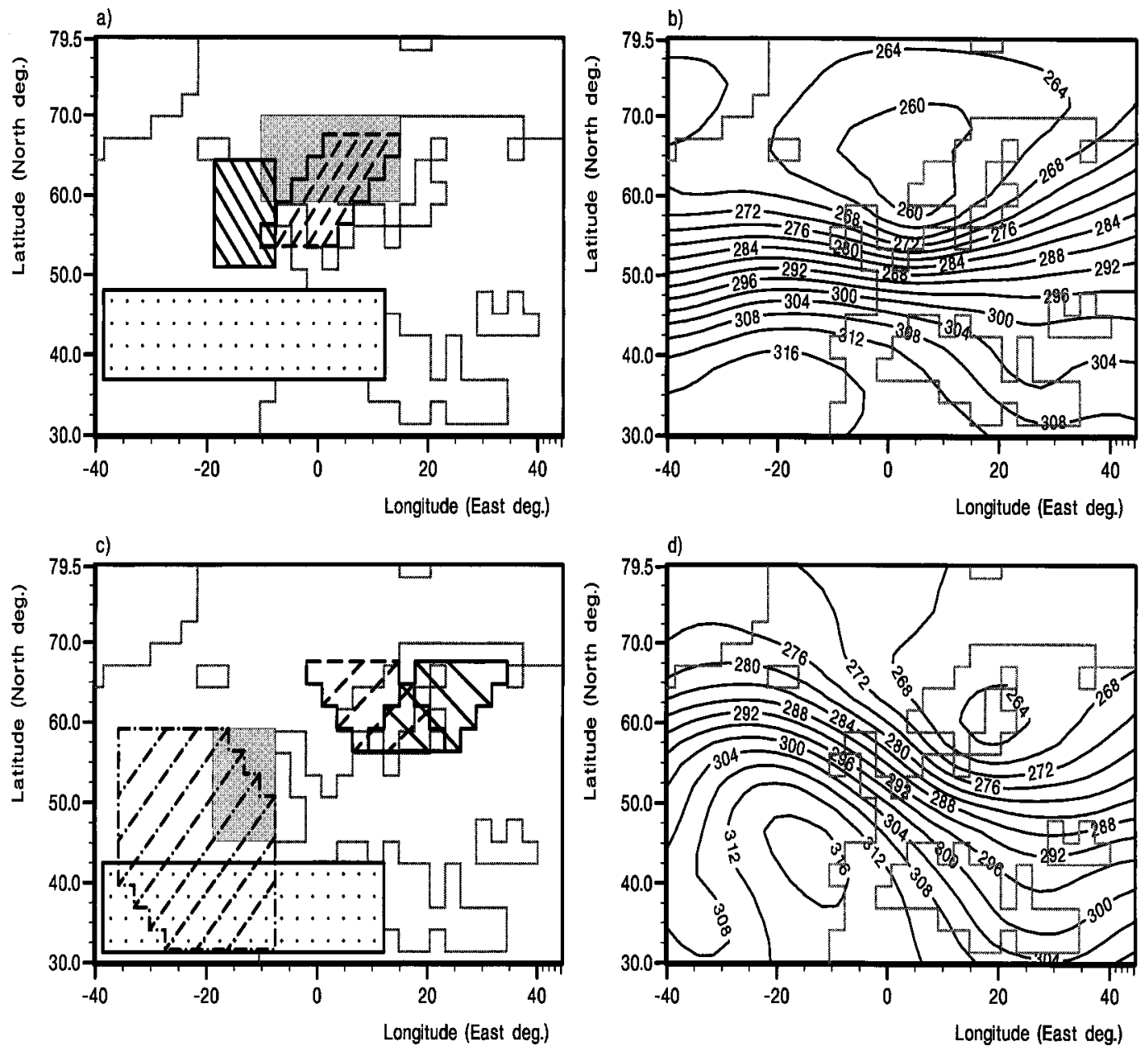

Fig. 2. Masks for the analysis of the geopotential heights in $700 \mathrm{hPa}$. (a) Westerly type, (c) northwesterly type. The average geopotential heights (gpdam) in $700 \mathrm{hPa}$ of all the storm weather situations in the period 1979-1993 are shown in (b) for the westerly and (d) for the northwesterly type.

pressure area in $700 \mathrm{hPa}$. Then the average of the 4 and the 12 grid points is calculated. If the difference is larger than 45 gpdam the first condition of this criterion is fulfilled. Fig. 2a shows the areas of our mask where we look for the steering centre and the accompanying high pressure area. Within the grey or the dash-shaded area, we look for the 4 connected grid points with the lowest geopotential heights and within the dotted area we look for the 12 connected grid points with the highest geopotential heights. The average geopotential height of the shaded area has to be 30 gpdam below the average geopotential height of the dotted area in order to take the second positive decision on this criterion.

Flow regime northwesterly type: Storm weather situations within a circulation pattern of the northwesterly type show an Azores High northeastward shifted up to the westerly Biscay. The steering centre is over Fennoscandinavia, the Norwegian or the Baltic Sea. The way to detect the differences in the geopotential heights between the steering centre and the high pressure area is the same as for the westerly type. Only the value of the difference is 55 gpdam. Within the dash-shaded or 
shaded areas (Fig. 2c), we detect the 4 connected grid points with the lowest geopotential heights, and within the dash-dot-shaded area, we look for the 12 connected grid points with the highest geopotential heights. The difference between the average geopotential height of the grey area and the average geopotential height of the dotted area has to be below 15 gpdam in order to make a positive decision.

Baroclinicity: For both groups of storm weather situations the threshold value for the baroclinicity is $0.018 \mathrm{~K} \mathrm{~km}^{-1}$ in a meridional direction. The area where we look for this threshold value is the North Atlantic at a height of $700 \mathrm{hPa}$. For the westerly type the area of interest is between $45^{\circ} \mathrm{N}-60^{\circ} \mathrm{N}$ and for the northwesterly type between $55^{\circ} \mathrm{N}-70^{\circ} \mathrm{N}$ within $40^{\circ} \mathrm{W}-0^{\circ}$.

Relative topography $500 / 1000 \mathrm{hPa}$ : What is typical of storm weather situations is a high relative topography of the warm sector. One way of checking this is the relative topography $500 / 1000 \mathrm{hPa}$. The threshold value for the westerly type is 534 gpdam and for the northwesterly type 528 gpdam in order to make a positive decision. For the westerly type the area of interest is between $52^{\circ} \mathrm{N}-62^{\circ} \mathrm{N}$ within $5^{\circ} \mathrm{W}-10^{\circ} \mathrm{E}$. and for the northwesterly type between $55^{\circ} \mathrm{N}-65^{\circ} \mathrm{N}$ within $10^{\circ} \mathrm{W}-20^{\circ} \mathrm{E}$. Whenever the average relative topography of 6 connected grid points within this area is larger than the threshold value, the first condition is fulfilled. Second, the longitudinal difference of the relative topography from boxes $(3 \times 2$ grid points) within the defined areas to boxes with a distance of $8.4^{\circ}$, were calculated. The threshhold value is 6 gpdam in order to take the second positive decision of this criterion.

Mixing ratio: What is also typical of storm weather situations is heavy precipitation; a way of checking this is the temporary change in the mixing ratio in a defined area. The area where we look for the temporary change in the mixing ratio is the same as for the relative topography. The height is the $700 \mathrm{hPa}$ level. If the average temporary change in the mixing ratio of 6 connected grid points within this area is larger than the threshold value, this criterion of the classification is fulfilled. The threshold values are $-1.8 \mathrm{~g} \mathrm{~kg}^{-1}$ for the westerly type and $-1.2 \mathrm{~g} \mathrm{~kg}^{-1}$ for the northwesterly type in $12-24$ hours.

3.2.2. The choice and the verification of the classification routine. The above-mentioned criteria in themselves yield a variety of positive decisions. In our classification routine we need the positive decision of all the single criteria. We start our coupling with the condition flow regime, than we look for the criteria baroclinicity, relative topography and mixing ratio taking into account the temporary shifting between the single criteria. From these three intersections the overall intersection is calculated (Fig. 3).

The verification of this classification routine with the ECMWF Re-Analysis and the homogenized time series of the wind speed of Norderney shows that $85 \%$ of all observed storm weather situations of the westerly and the northwesterly type are detected. Strong wind situations are also detected with a wind speed of approximate $16 \mathrm{~m} \mathrm{~s}^{-1}$ (Bft 7). The reason for is that it is impossible to give such sharp definitions of the large-scale parameters and the result is that not only weather situations with a wind speed of more than $17.2 \mathrm{~m} \mathrm{~s}^{-1}$ (storm weather situations, Bft 8) are detected. The average $10 \mathrm{~m}$ wind speed of all the weather situations which are detected with our classification routine is $17.8 \mathrm{~m} \mathrm{~s}^{-1}$ for the westerly and $17.5 \mathrm{~m} \mathrm{~s}^{-1}$ for the northwesterly type. The $15 \%$ of the observed storm weather situations which are not detected are those without a distinct high pressure area. In view of the separation of the westerly and the northwesterly types those events are not chosen. The application of the routine also shows that all the detected situations in the ECMWF Re-Analysis are strong wind or storm weather situations.

\section{Results}

The results of the seasonal distribution of strong wind and storm weather situations are shown in Fig. 4. For the German Bight and the southern Baltic, one model grid point is selected for this presentation, because the seasonal distribution of strong wind and storm weather situations of the other model grid points shows the same results. It can be seen that in the model simulation the winter season is the most favoured for these 


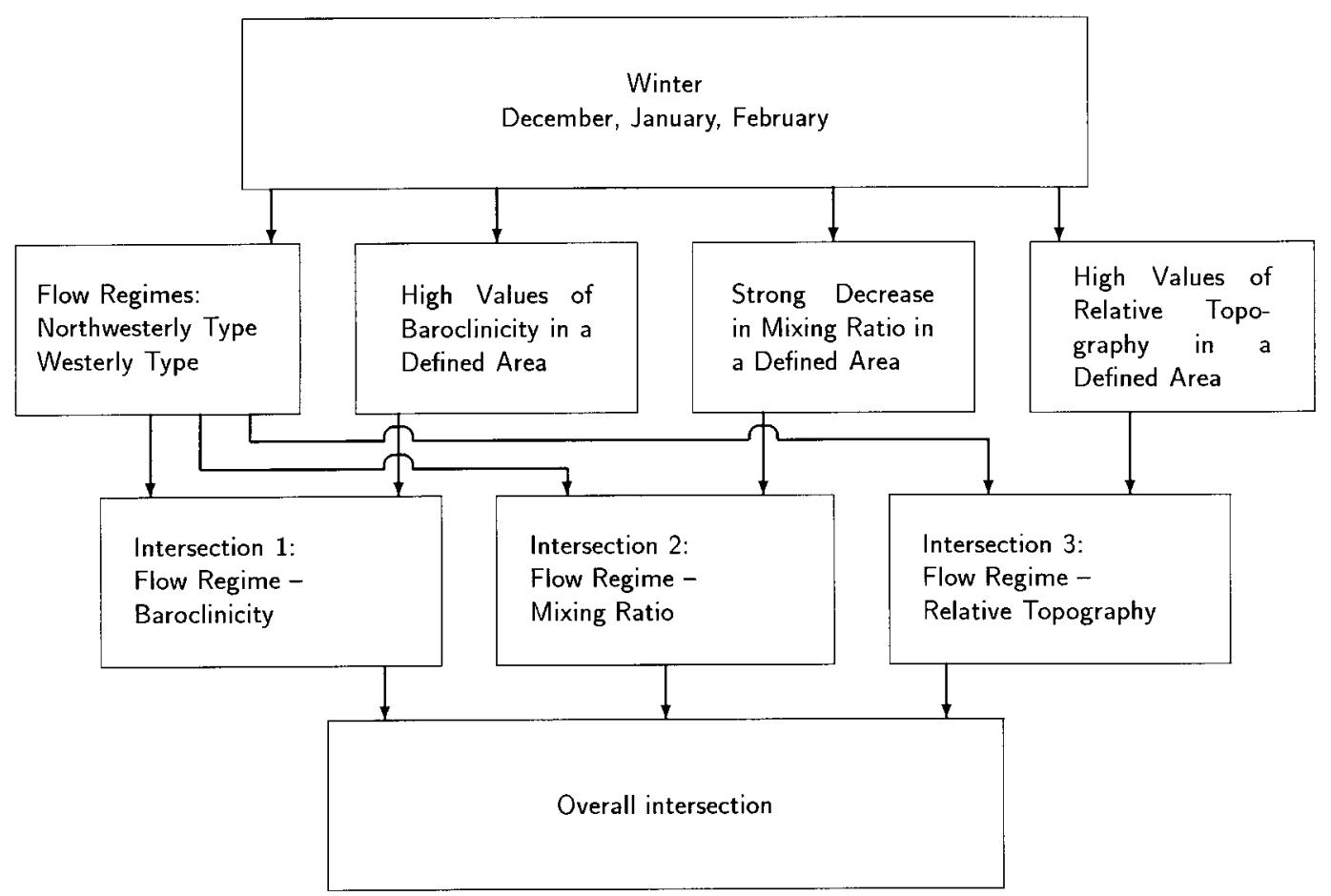

Fig. 3. Flow diagram of the objective classification routine for detecting strong wind and storm weather situations in coarse resolution models.

weather situations. Events with a wind force of Bft 6 have a frequency of occurrence of more than $40 \%$ (Fig. $4 \mathrm{a}, \mathrm{c}$ ) and events of Bft 7 and more have a frequency of occurrence of more than $50 \%$ (Fig. 4b, d) in the simulation in winter. In observations this season is favoured as well, but with a lower percentage. The seasonal distribution of strong wind and storm weather situations in winter and autumn is more similar in observations than in simulation. In summer, strong wind and storm weather situations in the German Bight often result from developments on the regional scale, whereas climate models like the ECHAM3/T42 are not able to resolve them. Storm weather situations like those which occurred in August 1990 are rare but they are not negligible. On the 20/21 August 1990 a storm cyclone resulted in westerly winds with a wind force of Bft 9 to 10 in the German Bight.

Table 1 shows the number of strong wind and storm weather situations for Norderney, Boltenhagen and the corresponding model grid points at 12 UTC in the periods considered. It can be seen that there are only noticable differences between observations and climate model simulation for Boltenhagen and the corresponding model grid point for Bft 7 and more. To compare the quantitative distribution of events with a wind force of Bft 6 and more in simulation and observations we chose Norderney station and the corresponding model grid point. Table 5 shows the number of events with a wind force of Bft 6 and more. The climate model yields approximately $35 \%$ more events of Bft 6 and more than observed in DJF. It is to consider that a GCM with a Gaussian grid of $2.8^{\circ}$ is not able to reproduce the exact wind climate of observation. But if there is an overestimation of events with a wind force of Bft 6 and more in DJF (30 year period) of 35\% the reason could not be explain by the horizontal resolution of the climate model.

The 30-year monthly average wind speed for the homogenized time series of Norderney and the selected grid points are presented in Fig. 5. It can be seen that the wind speed in summer is under- and in winter is overestimated in the 

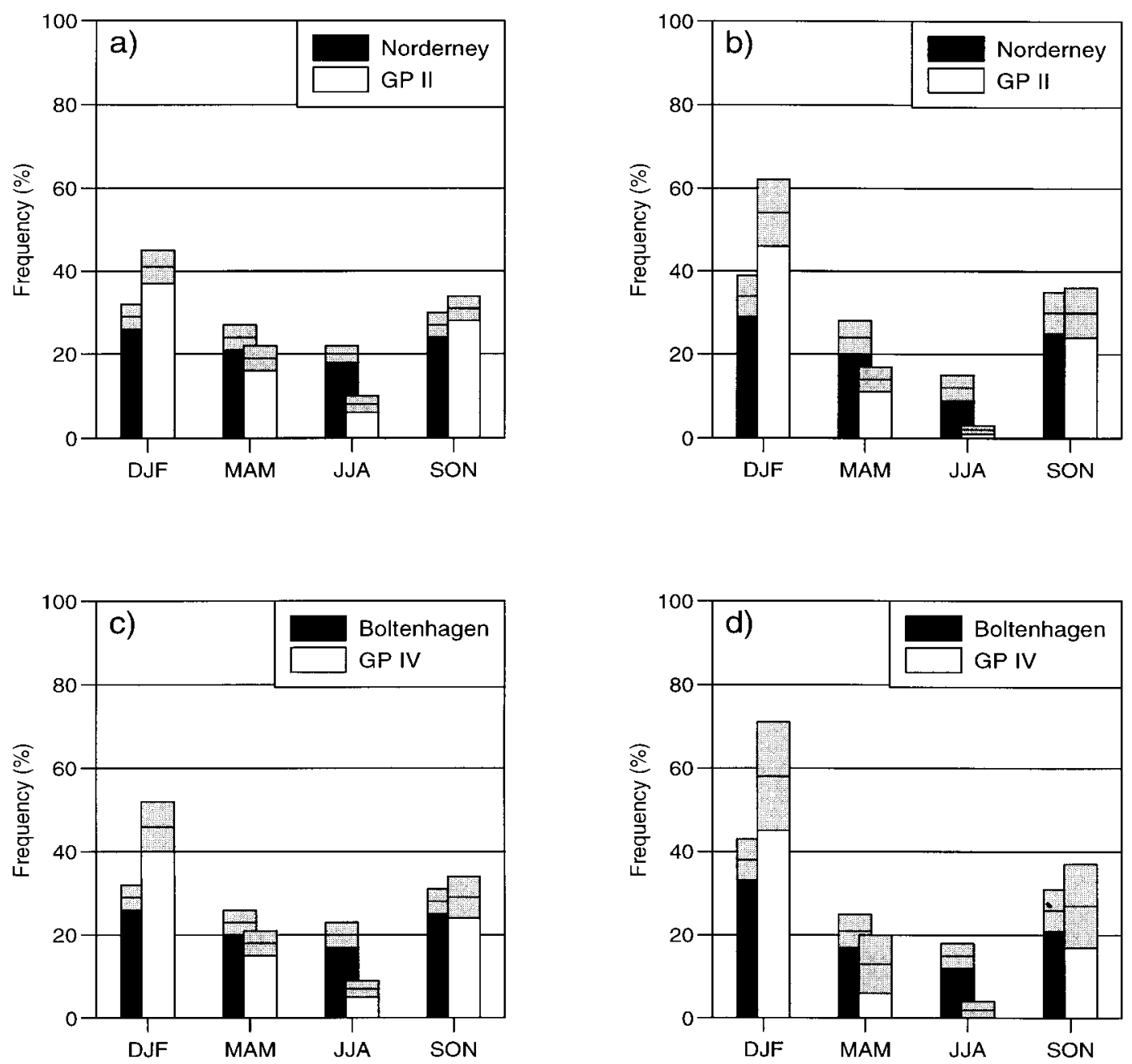

Fig. 4. The seasonal distribution in per cent of strong wind and storm weather situations. The light grey section marks the 95\% confidence level. (a) Bft 6 and (b) Bft 7 and more for the region of the German Bight. (c) Bft 6 and (d) Bft 7 and more for the southern Baltic Sea.

Table 5. Number of events with a wind force of Bft 6 and more for Norderney and the corresponding model grid point at 12 UTC; the period is 30 years

\begin{tabular}{lcc}
\hline & Norderney & GP II \\
\hline DJF & 631 & 867 \\
MAM & 504 & 367 \\
JJA & 357 & 141 \\
SON & 593 & 588 \\
\hline
\end{tabular}

simulation. The underestimation of the $10 \mathrm{~m}$ wind speed in summer could be explained by regional scale effects which could not be resolved by the climate model. These are for example land- and sea-breeze effects, developments of cyclones on a regional scale, especially in coastal regions, and effects which are caused by thermals and turbulence in the boundary layer (Hasse, 1974; Luthardt and Hasse, 1981). In winter the ECHAM3 shows a strong zonalisation of the large-scale flow in Europe. The North Atlantic storm tracks are too strong and their downstream ends too far into the continent (Kaurola, 1997). This results in an

Tellus 50A (1998), 4 


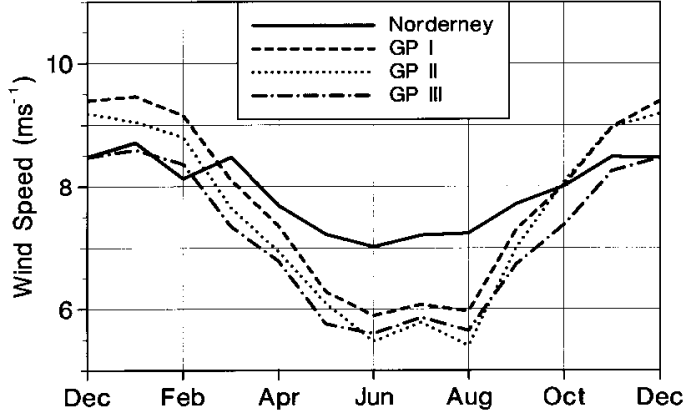

Fig. 5. The 30-year monthly average 12 UTC $10 \mathrm{~m}$ wind speed for the homogenized time series of Norderney and the grid points GP I-III from the climate model simulation.

overestimated warm air advection and windspeed (Wild et al., 1996; Marinucci et al., 1995).

The objective classification routine for detecting strong wind and storm weather situations was used to validate the large-scale parameters of single strong wind and storm weather situations in the climate model simulation. Only if all the criteria laid down in observations (see Section 3) are fulfilled is the decision positive. The strong wind and storm weather situations in the CTRL have the same flow regime as in observations. All the further criteria considered (relative topography, mixing ratio and baroclinicity) which are typical of strong wind and storm weather situations in observations are simulated quite realistically by the climate model.

The application of the objective classification routine to the ECMWF Re-Analysis and the ECHAM3/T42 CTRL shows that the frequency of strong wind and storm weather situations of the westerly type is overestimated in the CTRL (Table 6) in winter. The frequency of the northwesterly type is approximately the same in observations and CTRL. Possible reasons for this are differences in the mixing ratio and temperature between CTRL and observations. Fig. 6 shows the differences in the average mixing ratio and the temperature in $700 \mathrm{hPa}$ for autumn and winter. Autumn shows the best agreement of strong wind and storm weather situations in observations and simulation. In this season, the differences in the temperature between ECMWF Re-Analysis and CTRL for Europe are approximately zero. The difference in the mixing ratio is approximately
Table 6. Number of detected strong wind and storm weather situations (Bft 7 and more) in winter for the area of the German Bight in the ECHAM3/T42 $C T R L$ and the ECMWF re-analysis with the objective classification routine

\begin{tabular}{lcc}
\hline & $\begin{array}{c}\text { Westerly } \\
\text { type }\end{array}$ & $\begin{array}{c}\text { Northwesterly } \\
\text { type }\end{array}$ \\
\hline ECMWF-ANALYSES & & \\
$\quad$ 1979-1993 & 187 & 97 \\
CTRL & & \\
$\quad$ Model years 11-25 & 206 & 93 \\
Model years 26-40 & 223 & 85 \\
\hline
\end{tabular}

$20 \%$ for the North Sea and Scandinavia. In winter the temperature difference is in the range of $1.5 \mathrm{~K}$ and the mixing ratio difference is approximately $35 \%$.

Strong wind and storm weather situations of the westerly type strongly depend on an aboveaverage warm warm-sector with high humidity. The climate model simulation yields an overestimation of the humidity and the temperature in winter. This could be a possible reason for the overestimation of those events. Furthermore, European large-scale weather patterns of the westerly type are generally overestimated in the climate model simulation (Enke and Spekat, 1997). As a consequence of this there are more cyclones of the westerly type which are able to become a storm cyclone than of other European large-scale weather patterns.

\section{Conclusions}

The study shows that the number of strong wind and storm weather situations is approximately the same in climate model simulation and observations for the area of the German Bight and the southern Baltic. Differences exist for the seasonal distribution of these events. In the ECHAM3/T42 CTRL the winter is the most favoured season for strong wind and storm weather situations in the German Bight and the southern Baltic. However occurrences of these weather situations in winter are significantly overestimated in the climate model simulation. In contrast to winter, autumn shows considerable 

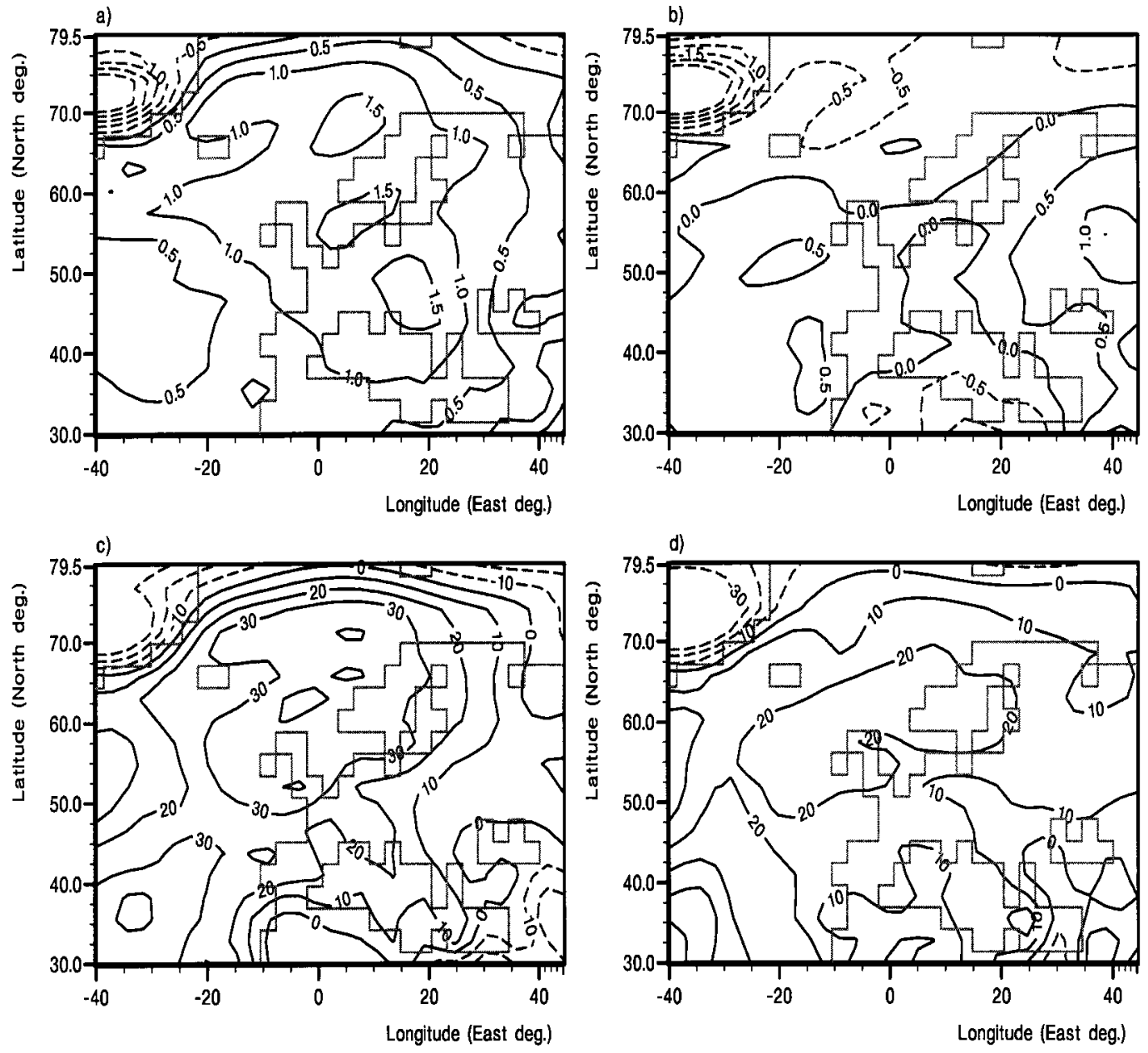

Fig. 6. Differences in the temperature in $\mathrm{K}$ and the mixing ratio in $\%$ between ECHAM3/T42 CTRL and ECMWF Re-Analysis in $700 \mathrm{hPa}$. (a) DJF temperature, (b) SON temperature, (c) DJF mixing ratio and (d) SON mixing ratio.

agreement in this investigation between observation and simulation.

A comparision between ECHAM3/T42 CTRL and ECMWF Re-Analysis with the objective classification routine presented shows an overestimation of strong wind and storm weather situations in the simulation in winter as well. This overestimation results from situations of the westerly type. The single strong wind and storm weather situations in the ECHAM3/T42 CTRL have the same flow regime as in observations. All the further criteria considered (relative topography, mixing ratio and baroclinicity) which are typical of single strong wind and storm weather situations in observations are simulated quite realistically by the climate model.

\section{Acknowledgements}

The results of the 30-year period of the ECHAM3/T42 CTRL were kindly provided by the Max-Planck-Institut für Meteorologie, Hamburg. In particular we would like to thank Arno Hellbach, who gave us assistance in copying the data from the archives of the Deutsches Klimarechenzentrum (DKRZ) in Hamburg. For data transfer we used a software tool developed 
by Dr. Raasch and Mr. Schade of the Institut für Meteorologie und Klimatologie Hannover. The observational data were obtained from the German Weather Service (DWD). Here our special thanks goes to Mr. Bauer, Dr. Berents and Dr. Wagner from the Seewetteramt Hamburg for providing the wind measurement data. Financial support was provided by the German Federal Ministry of Education, Science, Research and Technology (BMBF) through grant $03 \mathrm{~F} 0141 \mathrm{~A}$, 01 LK 9321/7 and TK 558-RTB 04.1 P4.

\section{Appendix}

\section{The European large-scale weather patterns}

In this appendix, a description of the European large-scale weather patterns used from the catalogue by Hess and Brezowsky (Gerstengarbe et al., 1993 ) is given. A large-scale weather pattern ("Großwetterlage") is defined as a tropospheric pressure and/or current pattern, which is unchanged in its essential features for a minimum of 3 days, especially in the location of the steering centres and frontal zones (Brezowsky et al., 1951). We classify the European large-scale weather patterns used as follows:

\section{(a) Westerly type}

WZ: Cyclonic west weather condition. Mainly cyclonic conditions in central Europe. The Azores high is in a normal position with a possible extension to south France. Over the North Atlantic and the Norwegian Sea is a low pressure area. The frontal zone lies in its normal position between $50^{\circ} \mathrm{N}$ and $60^{\circ} \mathrm{N}$.

WA: Anticyclonic west weather condition. Mainly anticyclonic conditions in central Europe. The Azores high may extend to South Germany and the centre of the low pressure area is most cases north $65^{\circ} \mathrm{N}$. The frontal zone is shifted northward to approximately $60^{\circ} \mathrm{N}$.

WS: Southerly west weather condition. The Azores high extends to North Africa and the centre of the low pressure area is south of $60^{\circ} \mathrm{N}$. The frontal zone is orientated from the Irish Sea to east Europe.
WW: Angular west weather condition. Usually the Azores high has a ridge over the Biscay. A blocking high pressure area is located over Russia. The frontal zone lies between $50^{\circ} \mathrm{N}$ and $60^{\circ} \mathrm{N}$ with a strong north turn at the edge of the Russian high pressure area.

SWZ: Southwest cyclonic weather condition. Mainly cyclonic conditions in central Europe. The frontal zone is located between a high pressure area over the Ukraine with an extension to North Africa and an extensive low pressure area over the middle North Atlantic to Ireland. It is reached from the Biscay to the British Isles and Scandinavia.

SWA: Southwest anticyclonic weather condition. Mainly anticyclonic conditions in central Europe. The frontal zone is located between an extensive high pressure area over southern Europe and the Mediterranean Sea and an extensive low pressure area over the middle North Atlantic. It is orientated from the Irish to the Baltic Sea.

(b) Northwesterly type

NWZ: Cyclonic northwest weather condition. Mainly cyclonic conditions in central Europe. There is a strong frontal zone between a nonblocking subtropical high pressure area, northeastward shifted up to the westerly Biscay, and an extensive low pressure area over Scotland, the Norwegian Sea and/or Scandinavia.

NWA: Anticyclonic northwest weather condition. Mainly anticyclonic conditions in central Europe. There is frontal zone with a weak anticyclonal curvature between a non-blocking subtropical high pressure area, northeastward shifted up to west Europe, and a low pressure area over Fennoscandinavia and the Norwegian Sea.

NZ: Cyclonic north weather condition. Mainly cyclonic conditions in central Europe. There is a blocking high pressure area over the easterly North Atlantic or a high pressure bridge reaching from the Iberian Peninsula to Polar areas. Over Fennoscandinavia is an extensive low pressure area. The frontal zone is orientated northeastward to Iceland.

NA: Anticyclonic north weather condition. Mainly anticyclonic conditions in Central Europe. A high 
pressure area is located over the British Isles, the Norwegian and the North Sea. In some cases there is a high pressure bridge reaching from the Iberian Peninsula to Polar areas. An extensive low pressure area (a trough is also possible) is located over east Europe.
TRM: Trough central Europe. A trough over north and central Europe is located on the edge of a high pressure area over the easterly North Atlantic. The frontal zone reaches from northwest to south Europe and turns back to northeast Europe further on.

\section{REFERENCES}

Bengtsson, L., Botzet, M. and Esch, M. 1996. Will greenhouse gas-induced warming over the next 50 years lead to higher frequency and greater intensity of hurricanes? Tellus 48A, 57-73.

Brezowsky, H., Flohn, H. and Hess, P. 1951. Some remarks on the climatology of blocking action. Tellus 3, 191-194.

Cubasch, U., Hasselmann, K., Höck, H., MaierReimer, E., Mikolajewicz, U., Santer, B. D. and Sausen, R. 1992. Time-dependent greenhouse warming computations with a coupled ocean-atmosphere model. Climate Dyn. 8, 55-69.

DKRZ. 1994. The ECHAM3 atmospheric general circulation model. Max-Planck-Institut für Meteorologie, Technical Report No. 6, Hamburg, Germany.

Dukes, M. D. G. and Palutikof, J. P. 1995. Estimation of extreme wind speeds with very long return periods. J. Appl. Meteor. 34, 1950-1961.

Enke, W. and Spekat, A. 1997. Downscaling climate model outputs into local and regional weather elements by classification and regression. Climate Research 8, 195-207.

Gerstengarbe, F.-W., Werner, P. C., Busold, W., Rüge, U. and Wegener, K.-O. 1993. Katalog der Großwetterlagen Europas nach Paul Hess und Helmuth Brezowsky 1881-1992; 4., vollst. neu bearb. Aufl. Ber. Dt. Wetterd. Nr. 113, Selbstverlag des Deutschen Wetterdienstes, Offenbach am Main, Germany.

Hasse, L. 1974. Note on the surface-to-geostrophic wind relationship from observations in the German Bight. Bound.-Layer Meteor. 6, 197-201.

Kaminsky, F. C., Kirchhoff, R. H., Syu, C. Y. and Manwell, J. F. 1991. A comparison of alternative approaches for the synthetic generation of a wind speed time series. J. Sol. Energy Eng. 113, 280-289.

Kaurola, J. 1997. Some diagnostics of the northern wintertime climate simulated by the ECHAM3 model. J. Climate 10, 201-222.

Kirchhoff, R. H., Kaminsky, F. C. and Syu, C. Y. 1989. Synthesis of wind speed using a Markov process. In Proc. Eight Wind Energy Symp., Amer. Soc. Mech. Eng., Houston, 17-22.

König, W., Sausen, R. and Sielmann, F. 1993. Objective identification of cyclones in GCM simulations. J. Climate 6, 2217-2231.
Luthardt, H. and Hasse, L. 1981. On the relationship between surface and geostrophic wind in the region of the German Bight. Contrib. Atmos. Phys. 54, 222-237.

Marinucci, M. R., Giorgi, F., Beniston, M., Wild, M., Tschuck, P., Ohmura, A. and Bernasconi, A. 1995. High resolution simulations of January and July climate over the western alpine region with a nested regional modeling system. Theor. Appl. Climatol. 51, 119-138.

Miller, M. J., Beljaars, A. C. M. and Palmer, T. N. 1992. The sensitivity of the ECMWF model to the parameterization of evaporation from the topical oceans. J. Climate 5, 418-434.

Roeckner, E., Arpe, K., Bengtsson, L., Brinkop, S., Dümenil, L., Esch, M., Kirk, E., Lunkeit, F., Ponater, M., Rockel, B., Sausen, R., Schlese, U., Schubert, S. and Windelband, M. 1992. Simulation of the present-day climate with the ECHAM model: impact of model physics and resolution. Max-Planck-Institut für Meteorologie, Report No. 93, Hamburg, Germany.

Sausen, R., König, W. and Sielmann, F. 1995. Analysis of blocking events from observations and ECHAM model simulations. Tellus 47A, 421-438.

Schmidt, H. and Pätsch, J. 1992. Meteorologische Messungen auf Norderney und Modellrechnungen. Die Küste 54, 131-142.

Von Storch, H. 1995. Inconsistencies at the interface of climate impact studies and global climate research. Meteorol. Z., N. F. 4, 72-80.

Von Storch, H. and Reichardt, H. 1997. A scenario of storm surge statistics for the German Bight at the expected time of doubled atmospheric carbon dioxide concentration. J. Climate 10, 2653-2662.

Wild, M., Dümenil, L. and Schulz, J.-P. 1996. Regional climate simulation with a high resolution GCM: surface hydrology. Climate Dyn. 12, 755-774.

Zielke, W., Mayerle, R., Kück, F., Hoyme, H., Groß, G., Roth, R., Nielinger, J. and Busch, U. 1997. Auswirkungen von Klimaänderungen auf die Wasserstände und Windverhältnisse an der deutschen Nordseeküste. Abschlußbericht BMBF Projekt Nr. 03F0141A, Institut für Strömungsmechanik und Elektronisches Rechnen im Bauwesen der Universität Hannover und Institut für Meteorologie und Klimatologie der Universität Hannover, Germany. 